International Journal of Scholarly Papers for Media and Communications

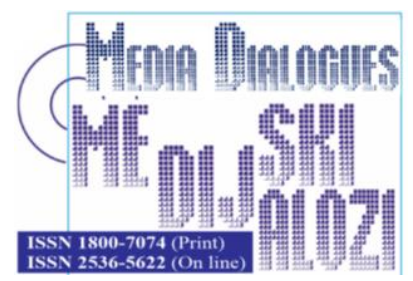

Draskovic, M., Dorokhova, L. (2012), ,Steve Jobs -Visionary and Manager Who Was Walking on Iclouds", Media Dialogues / Medijski dijalozi, Vol. 14, No. 3, pp. 15-22.

\title{
Steve Jobs -Visionary and Manager Who Was Walking on Iclouds
}

\author{
Associate Professor MIMO DRASKOVIC, \\ University of Montenegro, Faculty of Maritime Studies, \\ Kotor, Montenegro \\ Assistant professor LUDMILA DOROKHOVA, \\ Department of Management and Marketing in Pharmacy, \\ National Pharmaceutical University, \\ Kharkiv, Ukraine
}

\begin{tabular}{|c|c|}
\hline $\boldsymbol{A} \boldsymbol{R} \boldsymbol{T} \boldsymbol{I C L} \boldsymbol{E}$ & Received: October 03, 2020 / Revised from: November 0,1 2020 \\
$\boldsymbol{I N F \boldsymbol { O }}$ & Accepted: December 02, 2020 / Available online: January 15, 2021 \\
\hline DOI & doi.org/10.14254/1800-7074/14-1/2 \\
\hline
\end{tabular}

\begin{abstract}
Virtually, all human beings are complex creatures. We are full of intricacies some of which we will never be aware of, such is human nature. We all have inherent contradictions, we are hypocritical and we are inconsi- stent. All of this, together with our choices, makes us who we are, unique in a billions. Steve Jobs, the cofounder of Apple, was one such person. His self-belief and ability to convince others hel-
\end{abstract}


ped found one of the most successful companies in the world. He even managed to convince a large following of people that his company was not a company at all. The aim of this paper is to present Steve Jobs as a manager - the manager of the most secretive companie in the world.

\section{KEYWORDS:}

Steve Jobs, Apple, Manager, Visionary, Media, communications .

In the Old Testament there was the first apple, the forbidden fruit of the Tree of Knowledge, which with one taste sent Adam, Eve, and all mankind into the great current of History.

The second Apple was Isaac Newton's, the symbol of our entry into the age of modern science.

The Apple Computer symbol.... represents the third Apple, the one that widens the paths of knowledge leading toward the future.

Jean-Louis Gassée

(A former President of Apple Products)

\section{INTRODUCTION}

Over the past 100 years, management theory has followed a smooth trajectory, from enslavement to empowerment. Silicon Valley has always been at the forefront of this kind of egalitarianism. The 20th century began with Taylorism - engineer Frederick W. Taylor's notion that workers are interchangeable cogs - but with every decade came a new philosophy, each advocating that more power be passed down the chain of command to division managers, group leaders, and workers themselves. In the 1940s, Bill Hewlett and David Packard pioneered what business author Tom Peters dubbed "managing by walking around", an approach that encouraged executives to communicate informally with their employees.

In 1977, Robert Greenle- af's Servant Leadership argued that CEOs should think of themselves as slaves to their workers and focus on keeping them happy. In the 1990s, Intel's executives expressed solidarity with the engineers by renouncing their swanky corner offices in favor of standard-issue cubicles. And today, if Google hasn't made itself a Greenleaf-esque slave to its employees, it's at least a cruise director: The Mountain View campus is famous for its perks, including in-house masseuses, roller-hockey games, and a cafeteria where employees gobble gourmet vittles 
for free. What's more, Google's engineers have unprecedented autonomy; they choose which projects they work on and whom they work with. And they are encouraged to allot 20 percent of their work week to pursuing their own software ideas.

The result? Products like Gmail and Google News, which began as personal endeavors.

Jobs, by contrast, was a notorious micromanager. No product escapes Cupertino without meeting Jobs' exacting standards, which are said to cover such esoteric details as the number of screws on the bottom of a laptop and the curve of a monitor's corners. "He would scrutinize everything, down to the pixel level", says Cordell Ratzlaff, a former manager charged with creating the OS X interface.

When it comes to Apple, we can talk about the management theory that is not written or established, but that, through ideas and works of Steve Jobs, changed the world. In short, Jobs has been ,secretive management theory“.

\section{1. „EVIL“ MANAGER WITH A POENT}

Apple's street address, One Infinite Loop, is a programming in-joke — it refers to a routine that never ends. But it is also an apt description of the travails of parking at the Cupertino campus. Like most things in Silicon Valley, Apple's lots are egalitari- an - there are no reserved spots for managers or higher-ups. Even if you're a Porsche- driving senior executive, if you arrive after 9 am, you should be prepared to circle the lot endlessly, hunting for a space.

But there was one Mercedes that didn't need to search for very long...

.... and it had belong to Steve Jobs.

If there's no easy-to-find spot and he's in a hurry, Jobs has been known to pull up to Apple's front entrance and park in a handicapped space (sometimes he takes up two spaces). It's become a piece of Apple lore - and a running gag at the company. Employees have stuck notes under his windshield wiper: "Park Different". They have also converted the minimalist wheelchair symbol on the pavement into a Mercedes logo.

Jobs' fabled attitude toward parking reflects his approach to business: For him, the regular rules do not apply.

Everybody is familiar with Google's famous catchphrase, "Don't be evil." It has become a shorthand mission statement for Silicon Valley, encompassing a variety of ideals that, proponents say, are good for business and good for the world: Embrace open platforms. Trust decisions to the wisdom of crowds. Treat your employees like gods. 
It's ironic, then, that one of the Valley's most successful companies ignored all of these tenets. Google and Apple may have a friendly relationship, but by Google's definition, Apple is irredeemably evil, behaving more like an old-fashioned industrial titan than a different-thinking business of the future. Apple operates with a high level of secrecy. It locks consumers into a proprietary ecosystem. And as for treating employees like gods? Yeah, Apple doesn't do that either.

Apple creates must-have products the old-fashioned way: by locking the doors and sweating and bleeding until something emerges perfectly formed. It's hard to see the Mac OS and the iPhone coming out of the same design-by-committee process that produced Microsoft Vista or Dell's Pocket DJ music player. Likewise, had Apple opened its iTunes-iPod juggernaut to outside developers, the company would have risked turning its uniquely integrated service into a hodgepodge of independent applications - kind of like the rest of the Internet, come to think of it.

And now observers, academics, and even some other companies are taking notes. Because while Apple's tactics may seem like Industrial Revolution relics, they've helped the company position itself ahead of its competitors and at the fore-front of the tech industry. Sometimes, evil works...

\section{JOBS - AUTOCRATS WITH CHARISMA}

At most companies, the red-faced, tyrannical boss is an outdated archetype, a caricature from Heal. Not at Apple. Whereas the rest of the tech industry may motiva- te employees with carrots, Jobs is known as an inveterate stick man. Even the most favored employee could find themselves on the receiving end of a tirade. Insiders ha- ve a term for it: the "hero-shithead roller coaster". "More than anywhere else I've worked before or since, there's a lot of concern about being fired", said one former Apple engineer.

But Jobs' employees remain devoted. That's because his autocracy is balanced by his famous charisma - he can make the task of designing a power supply feel like a mission from God. Andy Hertzfeld, lead designer of the original Macintosh OS, says Jobs imbued him and his coworkers with "messianic zeal." And because Jobs' appro- val is so hard to win, Apple staffers labor tirelessly to please him. "He has the ability to pull the best out of people", says Ratzlaff, who worked closely with Jobs on OS X for 18 months. "I learned a tremendous amount from him".

Apple's successes in the years since Jobs' return - iMac, iPod, iPhone - suggest an alternate vision to the worker-is-always-right school of management. In $\mathrm{Cu}$ pertino, innovation doesn't come from coddling employees and collecting whatever froth rises to the surface; it is the product of an intense, hard-fought process, where people's feelings are irrelevant. Some management theorists are coming around to Apple's way of thinking. "A certain type offorcefulness and psychologist at Stanford 
who wrote an appreciation of "great intimidators" - including Jobs (February 2006 Harvard Business Review).

Likewise, Robert Sutton's 2007 book, The No Asshole Rule, spoke out against workplace tyrants but made an exception for Jobs: "He inspires astounding effort and creativity from his people". A Silicon Valley insider once told Sutton that he had seen Jobs demean many people and make some of them cry. But, the insider added, "He was almost always right".

"Steve proves that it's OK to be an asshole," says Guy Kawasaki, Apple's former chief evangelist. "I can't relate to the way he does things, but it's not his problem. It's mine. He just has a different $O S^{\prime \prime}$.

Jobs was a complicated character and was certainly far from the nicest of people. What made him so unique was his ability to spot trends and go with them. $\mathrm{He}$ may not have been a great innovator. But perhaps he didn't have to be as he surrounded himself with people that could realise his aims for him.

He was a futurist. When it came to large scale, big-picture thinking in the computer industry Steve Jobs was unrivalled. Yet Steve Jobs had, not just a darker side, but a brutal uncaring selfishness without empathy that permeated his every exi- stence. Steve Jobs was, according to the author, Michael Maccoby, a productive narcissist. Maccoby writing in the Washington Post in 2009 stated: "Steve Jobs is one of the most creative business leaders of our time. His products combining technological innovation with beauty of design are a gift that keeps giving. But he is not a good model for others to imitate. Who would want to follow a leader who is often insulting to his subordinates, who uses people only as long as he needs them and then discards them, and who demands that they are on call at all hours? Some people would and do, because Jobs creates great products that change people's lives and those who can stand him are inspired by him and can also make a lot of money. Steve Jobs is unique, but he resembles other leaders who want to change the world. I call them productive narcissists..."

Some people who worked closely with Jobs for any long period of time have testified to this. Writer, Robert Cringely, who worked with Jobs during the early years of Apple, certainly was not enamoured with the personality of the head of Apple. He said: "Everyone in Steve Jobs's life went through three phases. They were either being seduced, ignored or scourged. And it all depended upon whether he needed you or not. If he nee- ded you he was your best friend and he would seduce you. And then you would work like a dog and if you weren't working hard enough he would scourge you. And ultimately he would throw you away... Steve ultimately betrayed everyone".

Despite this it is important to acknowledge the importance of Steve Jobs. He changed the nature of the computer industry by leading the way in transforming consumer patterns. Jobs didn't so much predict changes in trends as create them. His 
marketing ability was second-to-none. He created a narrative for Apple products which focused people's attention.

In 1984 he shifted the focus on a perceived battle, whether real or not, between IBM and Apple in what was a great marketing coup. Jobs succeeded in transforming a company into a movement. Instead of consumers Apple had followers. This gave the company unprecedented power and a voice that went beyond the normal constraints of a consumer products company.

\section{THE MEDIUM IS THE MESSAGE... AND MUCH MORE}

In 1964 Marshall McLuhan offered his now-famous dictum that "the medium is the message." Few people have done more to illustrate that than Steve Jobs. Apple's products have changed not just how we communicate but what we communicate and even, arguably, what we think. The phenomenon McLuhan identified was one of framing, of inadvertent shaping: a group that watches a political debate on television may have a different take on who won than the group that listened on the radio.

Jobs's approach had a teleological dimension. "A lot of times, people don't know what they want until you show it to them", he once said. With his products, the medium often made the message. Unlike something like Twitter or Facebook, where developers have seemed content to let users repurpose and improvise, Apple has a more interventionist ethos: here is the product, you should use it to do this, and if you need help, go to the Genius bar. It's a testament to his phenomenal career that this only seems like a part of his legacy.

To some extent, this is just as McLuhan predicted. Apple has a distinctive aesthetic that prioritises simplicity and straightforwardness. This aesthetic is just the surface of Apple's deeper design principle: that cutting-edge technology should be easy to use.

Ten years ago, this would have seemed bizarre. Now it is the norm, a common feature of high-tech products and a widely shared goal. The iPhone, the iPad and the MacBook are the medium; the message is that technology should be easy, intuitive, and fun.

But Apple's influence-and it feels right to use Apple and Jobs interchange- ablygoes beyond that. In so far as Apple was the first company to make this technology attractive to a general audience, it encouraged people to use computers for pleasure. Apple's stylish, user-friendly products fostered a greater willingness to spend time online, to blog, to tweet, to have constant access to a handheld computer.

Some of Steve Jobs' moves were market-driven. More often, though, Apple struck out alone with projects that seemed quixotic. Ultimately people gave Jobs the benefit of the doubt even on ideas that would have been scoffed at if they had come from another source. When Apple debuted the iPad, for example, consumers were 
suddenly game to embrace tablet computing, even though earlier tablets from other companies had never drawn much popular attention.

And one final note about medium and message... The Apple worl-dview has a significant point of internal dissonance, which is aptly summarised by its old exhortation to "Think different". That has long been taken to mean "think differently", but the medium gives the lie to this interpretation. Inside the Apple ecosystem, conformity is the order of the day: Apple products build on each other, with the effect that Mac users are somewhat locked in to both the company and its design metaphors. This has caused critics to grumble that despite their professed free-thinking, Apple aficionados are actually suffused with groupthink. It's an interesting irony. For a company that has demonstrated that the medium makes the message, it stands to reason that the medium will sometimes contradict the message, too.

\section{INSTEAD OF CONCLUSION: WHERE TO FROM HERE?}

The biggest question on everyone lips now is what will happen to Apple without its leader? What will befall the company? No one knows the answer to this. What we do know is that previously without Steve Jobs the company did poorly. Lacking the necessary focus it launched too many products causing sales to plummet. It had missed out on what makes Apple so successful, its cache. Having loads of products destroys the impression of prestige. To ask the question of whether the products truly were premium or not would miss the point. The fact that people perceived that they were was the most important aspect. Jobs played an integral part in this.

With Steve Jobs death the true question is can followers of Apple attribute the same status to the company's products or will they start to see them as vastly overpriced compared to their competitors. Only time will tell... For now, we know that the religious side of the Mac phenomenon has became particularly acute. Cards and messages such as the following were to be found at the Apple stores around the world:

"Thank you for changing the world for the better"

"You changed my life"

"You made me a believer"

That's it... That's the end...

"See you in the 'Cloud' Steve"

\section{REFERENCES}

http://tech.fortune.cnn.com/2011/08/25/how-apple-works-inside-the-worldsbiggest- startup/ 
http://www.slideshare.net/kaushiik10/project-apple-computers

http://www.andreaslindinger.net/downloads/strategicmgmts-lindingeretal.pdf

http://appleinnovation.blogspot.com/

http://www.theglobeandmail.com/news/technology/tech-news/steve-jobs-the-manwho-changed-your-world/article2192664 